\title{
JNK Inhibitor CC-401
}

National Cancer Institute

\section{Source}

National Cancer Institute. JNK Inhibitor CC-401. NCI Thesaurus. Code C49095.

A second generation ATP-competitive anthrapyrazolone c-Jun $\mathrm{N}$ terminal kinase (JNK) inhibitor with potential antineoplastic activity. Based on the chemistry of SP600125, another anthrapyrazolone inhibitor of JNK, CC-401 competitively binds the ATP binding site of JNK, resulting in inhibition of the phosphorylation of the $\mathrm{N}$-terminal activation domain of transcription factor c-Jun; decreased transcription activity of c-Jun; and a variety of cellular effects including decreased cellular proliferation. 